\title{
Long-term evaluation of a micronutrient-fortified biscuit used for addressing micronutrient deficiencies in primary school children
}

\author{
ME van Stuijvenberg ${ }^{1, *}$, MA Dhansay ${ }^{1}$, CM Smuts $^{1}$, CJ Lombard $^{2}$, VB Jogessar ${ }^{3}$ and \\ AJS Benadé 1 \\ ${ }^{1}$ Nutritional Intervention Research Unit, Medical Research Council, PO Box 19070, Tygerberg 7505, South Africa: \\ ${ }^{2}$ Biostatistics Unit, Medical Research Council, PO Box 19070, Tygerberg 7505, South Africa: ${ }^{3}$ Department of \\ Haematology, Faculty of Medicine, University of Natal, PO Box 17039, Congella 4013, South Africa
}

Submitted 30 November 2000: Accepted 2 May 2001

\begin{abstract}
Objective: To evaluate the long-term effect on micronutrient status of a $\beta$-carotene-, iron- and iodine-fortified biscuit given to primary school children as school feeding. Design: Children receiving the fortified biscuit were followed in a longitudinal study for 2.5 years $(n=108)$; in addition, cross-sectional data from three subsequent surveys conducted in the same school are reported.

Setting: A rural community in KwaZulu-Natal, South Africa.

Subjects: Children aged 6-11 years attending the primary school where the biscuit was distributed.

Results: There was a significant improvement in serum retinol, serum ferritin, haemoglobin, transferrin saturation and urinary iodine during the first 12 months of the biscuit intervention. However, when the school reopened after the summer holidays, all variables, except urinary iodine, returned to pre-intervention levels. Serum retinol increased again during the next 9 months, but was significantly lower in a subsequent cross-sectional survey carried out directly after the summer holidays; this pattern was repeated in two further cross-sectional surveys. Haemoglobin gradually deteriorated at each subsequent assessment, as did serum ferritin (apart from a slight increase at the 42-month assessment at the end of the school year).

Conclusions: This study has shown that fortification of a biscuit with $\beta$-carotene at a level of $50 \%$ of the Recommended Dietary Allowance (RDA) was enough to maintain serum retinol concentrations from day to day, but not enough to sustain levels during the long school holiday break. Other long-term solutions, such as local food production programmes combined with nutrition education, should also be examined. The choice of the iron compound used as fortificant in the biscuit needs further investigation.
\end{abstract}

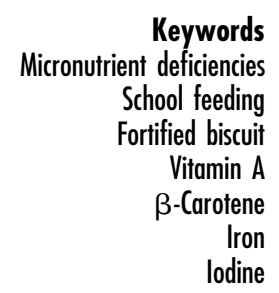

Micronutrient deficiencies, particularly of iron, iodine and vitamin A, are prevalent in developing countries worldwide $^{1}$ and can have an effect on the growth, development and immunity of children. The various strategies used for combating micronutrient deficiencies include high-dose supplementation, food fortification, nutrition education, and food diversification ${ }^{1}$. Of these, the food-based approach is probably the most sustainable and desirable approach to solve this problem. However, changing the dietary habits of a population is not easy and may take years to show an effect. Food fortification, on the other hand, offers a solution that gives more immediate results, and simultaneously reaches large segments of the population.
In a recent randomised controlled trial we evaluated the effect of a biscuit fortified with iron, iodine and $\beta$ carotene on the micronutrient status of primary school children from a poor rural community ${ }^{2}$. Compared with a control group, consumption of this biscuit resulted in a significant improvement in vitamin $\mathrm{A}$, iron and iodine status. Cognitive function and morbidity of these children were also favourably affected. The study concluded that a micronutrient-fortified biscuit is a feasible, practical and effective way of improving the micronutrient status of primary school children. There are several reasons why a biscuit is an ideal vehicle for fortification in school feeding. Firstly, a biscuit given to the child during the school day is perceived by the parent as a snack rather 
than a meal and therefore is unlikely to replace meals given to the child at home. Furthermore, a biscuit needs no preparation, it is easy to distribute, can easily be monitored, and has a long shelf life compared with other school feeding options.

The effect of this biscuit was evaluated over a period of 12 months $^{2}$. If, however, a fortified biscuit programme is to be implemented in primary schools, children may be exposed to this intervention for a period of several years. The effect of long-term exposure to such a programme, in terms of virtual elimination of micronutrient deficiencies, compliance, acceptability and sustainability, is not known. To answer this question the biscuit intervention was continued and the micronutrient status of the experimental group followed for a further 18 months. The aim of the present study therefore was to evaluate in a longitudinal study the effect of a micronutrient-fortified biscuit given to primary school children as school feeding over a period of 2.5 years (30 months). In addition, we report the data from three subsequent cross-sectional surveys conducted in the same school at 33, 42 and 45 months after the start of the original intervention. During this time the fortified biscuit continued to be distributed at the school.

\section{Methods}

\section{Study population and design}

The study population consisted of 6-11-year-old children attending the Ndunakazi Primary School, situated in a mountainous rural area $\sim 60 \mathrm{~km}$ north-west of Durban, KwaZulu-Natal, South Africa and serving a community characterised by low socio-economic status. These children formed the experimental arm $(n=115)$ of a randomised controlled trial in which the effect of a biscuit fortified with iron, iodine and $\beta$-carotene was studied over a period of 12 months $^{2}$.

After completion of the trial the biscuit intervention was continued; during this time the control group also received the fortified biscuit. We followed the children from the experimental group in a longitudinal study for an additional 18 months. The original study lasted from May 1995 to June 1996; blood was drawn before the start of the intervention and again after 6 (November 1995) and 12 months (June 1996) of intervention. Of the 115 children who completed the randomised controlled trial, the micronutrient status of 108 was assessed again in February 1997, when the school reopened after the summer holiday break, but before the biscuit programme for that year was resumed; and again in November 1997, i.e. after a total of 30 months of the biscuit programme.

The biscuits were distributed daily during the school week, during the first two hours of the school day by nutrition monitors (local people trained specifically for the project). Each child received three biscuits weighing $15 \mathrm{~g}$ each. No intervention took place during school holidays, weekends or public holidays; the biscuits were supplied for a total of 441 days during the 30-month intervention period. The children were dewormed ( $400 \mathrm{mg}$ albendazole) at 4-monthly intervals during the 12-month randomised controlled trial, and on a further three occasions during the subsequent 18-month followup period. Baseline results from the original study indicated that $34.3 \%$ of the study population was infected with one or more parasite, mostly Trichuris trichiura ${ }^{2}$. The study was approved by the Ethics Committee of the Medical Research Council and permission was obtained from the Department of Education, the headmaster of the school, and local community leaders. Informed consent was obtained from the parents or guardians of all participants.

\section{Fortification}

The shortbread-based biscuit was designed to provide $50 \%$ of the Recommended Dietary Allowance (RDA) ${ }^{3}$ for children 7-10 years old per three biscuits (i.e. $5 \mathrm{mg}$ iron (ferrous fumarate), $60 \mu \mathrm{g}$ iodine (potassium iodate) and $2.1 \mathrm{mg} \beta$-carotene). To enhance the absorption of iron each child was also provided with a cold drink fortified with vitamin C $(110 \mathrm{mg} / 150 \mathrm{ml})$. Each new batch of biscuits and cold drinks was analysed for micronutrient content to ensure that levels were maintained throughout the study. Shelf life in terms of micronutrient composition was at least 3 months; there were also no organoleptic changes during this period.

\section{Measurements}

Blood ( $5 \mathrm{ml}$ ) was obtained by venepuncture. A full blood count was performed by means of an automated cell counter (Coulter STKS, FL, USA). The rest of the blood was processed and stored at $-80^{\circ} \mathrm{C}$ until assayed. Serum ferritin was determined by an immunoradiometric assay (Ferritin MAb Solid Phase Component System, Becton Dickinson and Company, NY, USA), using an Auto Gamma 500C counting system (United Technologies Packard, IL, USA). Serum iron and total iron binding capacity (TIBC) were determined spectrophotometrically with a Technicon RA-1000 automated system, using a colorimetric method from Boehringer Mannheim, Germany. Transferrin saturation (TS) was calculated by expressing total serum iron as a percentage of TIBC. Serum retinol was determined by reversed-phase highperformance liquid chromatography (HPLC), based on the method described by Catignani and Bieri ${ }^{4}$. Urinary samples were collected and urinary iodine was determined spectrophotometrically using the Sandell-Kolthoff reaction $^{5}$. C-reactive protein (CRP) in serum was measured by particle-enhanced nephelometry (Behringwerke AG, Marburg, Germany). Compliance was closely monitored and recorded daily by the nutrition monitors using record sheets. Information on the acceptability of the biscuit, as well as breakfast patterns, was obtained by 
means of a short questionnaire administered at the various assessments.

\section{Additional cross-sectional data}

Data from three additional cross-sectional surveys conducted in the same school at 33, 42 and 45 months after the start of the biscuit intervention are also reported. A study, evaluating the effect of an $\omega 3$-fatty acid supplement on the cognitive function of primary school children, was conducted in this school during $1998^{6}$. To make sure that micronutrient deficiencies as confounding factors were excluded, we continued to supply the micronutrientfortified biscuit to all the children. We used this opportunity to obtain information on the vitamin $\mathrm{A}$ and iron status of the children from this school for a further 15 months. Two hundred and fourteen children were assessed in February 1998 at the start of a new school year and at a follow-up assessment in November 1998, and 223 again in February 1999, the beginning of the 1999 school year. Because they were not necessarily the same children as those surveyed in the original biscuit study, this phase of the study was no longer longitudinal, but rather cross-sectional; the estimated sample overlap between the original cohort and the February 1998 and February 1999 samples was 26\% and 17\%, respectively. For all three surveys, grade 1 pupils (i.e. new school entrants who had not been exposed to the biscuit intervention the year before) were excluded from our data set; all children thus had exposure to the biscuit programme for at least one year. Children were dewormed at 4-monthly intervals.

There were certain differences with regard to the fortification of the biscuit during this phase of the study. Due to the mandatory iodisation of salt that came into effect on 1 December 1995 in South Africa, the biscuit supplied to the children in this study no longer contained iodine. Also, instead of the ferrous fumarate, which was used as the iron fortificant during the first 30 months, a chelated form of iron (ferrous bisglycinate) was used as fortificant during this latter phase of the study. Vitamin C to enhance the absorption of iron was thus thought no longer to be required and the vitamin-C-fortified cold drink no longer supplied.

\section{Statistical analysis}

Data were analysed using the SPSS for Windows software program (version 9.0, SPSS Inc., IL, USA). Results are presented as means and standard deviations (SD); however, where values are not normally distributed, medians, together with the 10th and 90th percentiles, are given. Comparisons with regard to micronutrient status were made in relation to the immediately preceding time point, except for the second and third surveys, which were compared with baseline (these two surveys were part of the original randomised controlled trial where the efficacy of the biscuit was demonstrated against a control group, and are repeated as such in order to set the scene for what is to follow). White blood cell counts at each assessment were compared with baseline. The Wilcoxon signed rank test for paired data was used to compare longitudinal data and the Mann-Whitney $U$-test to compare cross-sectional data. $P$-values $<0.05$ were considered statistically significant.

\section{Results}

Table 1 gives the mean or median levels of the biochemical indicators of micronutrient status at the various time points during the longitudinal study, as well as at the three subsequent cross-sectional surveys. Serum retinol improved significantly during the first 12 months of intervention. However, at the 21-month assessment in February 1997, which took place shortly after the school reopened after the summer holidays, there was a significant decrease in serum retinol; biscuits were not distributed during school holidays. Retinol concentrations increased again during the next 9 months, but were significantly lower in the subsequent crosssectional survey carried out directly after the summer holiday; this pattern was repeated in the two further cross-sectional surveys, conducted before and after the holiday period. These fluctuations are also reflected in Fig. 1, where the prevalence of low serum retinol levels is given over time.

There was also a significant improvement in serum ferritin, haemoglobin and transferrin saturation during the first 12 months of intervention. However, when the school reopened after the summer holiday all three variables returned to pre-intervention levels. Haemoglobin showed a gradual deterioration at each subsequent assessment over the next two years. Serum ferritin, apart from an increase at the 42-month assessment at the end of the school year, also deteriorated. Transferrin saturation increased again between 21 and 30 months, but not by the same magnitude as during the first 12 months of intervention; transferrin saturation was not measured in the three subsequent cross-sectional surveys. The prevalences of low serum ferritin and haemoglobin levels over this period are given in Figs 2 and 3. White blood cell counts showed a gradual decline over time, with the values at the fourth, fifth, sixth, seventh and eighth surveys being significantly lower than that at baseline.

Because the majority of children (70\%) were not anaemic at the baseline assessment and therefore may have diluted the response to the intervention, we also report the iron status of the $30 \%$ that were anaemic (haemoglobin $<12 \mathrm{~g} \mathrm{dl}^{-1}$ ) separately for the 2.5-year period (Table 2). Again there was an increase in all indicators of iron status over the first 12 months, which was accompanied by a significant decline after the summer school holidays. Only serum iron and transferrin saturation showed a significant increase during the 


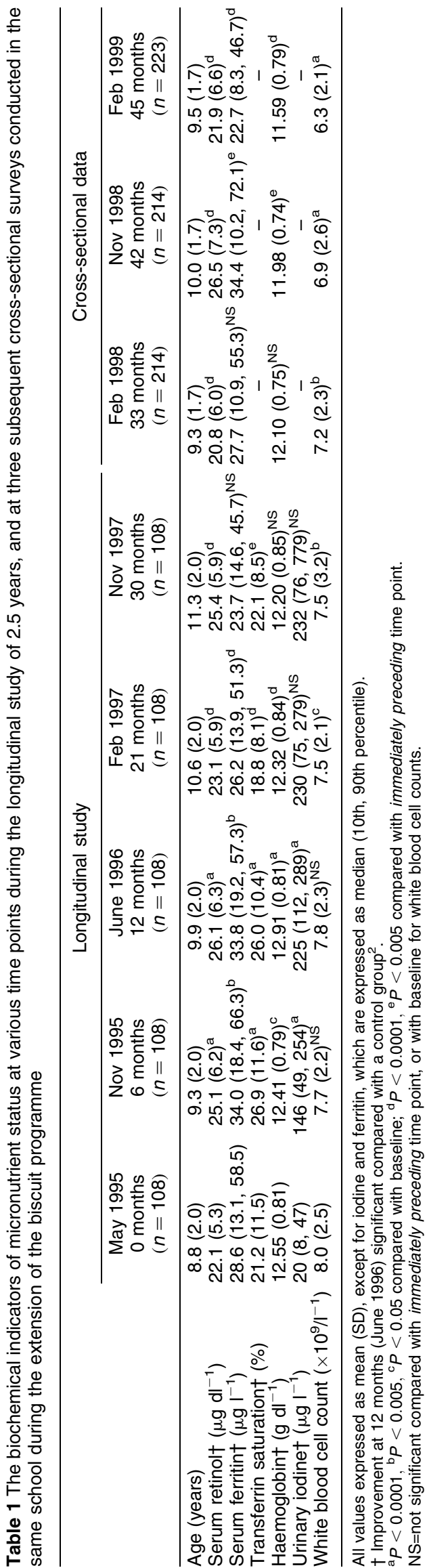

following 9 months, though this did not match the magnitude seen during the first 12 months of intervention; serum ferritin and haemoglobin remained unchanged.

The distribution of serum ferritin concentrations during the 2.5-year longitudinal study is illustrated in Table 3. Only 1.9\% (two children) had serum ferritin concentrations above $100 \mathrm{\mu g} \mathrm{l}^{-1}$ at the baseline assessment and there was no increase in the number of children in this category over the next 30 months (the highest concentrations for the five respective assessments were 122.6, 118.2, 142.8, 112.3 and $101.3 \mu \mathrm{g} \mathrm{l}^{-1}$ ). Not a single child had consistently high levels of serum ferritin throughout the study and in all cases ferritin levels above $100 \mu \mathrm{g} \mathrm{l^{-1 }}$ were associated with either elevated C-reactive protein or elevated white blood cell concentrations.

Urinary iodine improved significantly from baseline to 12 months (Table 1), and the prevalence of low urinary iodine dropped from $97.1 \%$ before the intervention to 4.8\% after the first 12 months of intervention (Fig. 4). This low prevalence was maintained for the rest of the longitudinal study. Urinary iodine was not measured at the subsequent cross-sectional surveys.

Compliance was defined as the number of days that a child received the biscuit expressed as a percentage of the total number of potential biscuit days; potential biscuit days (441 days during the first 30-month period) did not include weekends, school holidays or public holidays. The mean compliance was $92.4 \%$ during the first 12 months and $80 \%$ during the last 9 months of the longitudinal study. Reason for non-compliance was mostly absence from school and unavailability of the biscuit, which was due to problems experienced with the supply and delivery of the biscuits by the manufacturing company. Compliance during the cross-sectional phase of the study was 95\%. The taste of both the biscuit and cold drink was acceptable to all (100\%) of the children at both the 12 - and 30 -month assessments; $74 \%$ of the children at the 12 -month assessment and $78.5 \%$ of the children at the 30-month assessment indicated that they would prefer more than the three biscuits they were receiving.

Eighty-nine per cent of the children at the baseline assessment, and 90\%, 94\% and 90\% at the 6-, 12- and 30month assessments, respectively, reported eating breakfast before coming to school in the morning. Reasons for not eating breakfast were mainly 'late for school', 'no food available' or 'not hungry'.

\section{Discussion}

This study evaluated the effect on micronutrient status of a micronutrient-fortified biscuit, given to primary school children, over a period of 2.5 years. In addition crosssectional data from three subsequent surveys conducted in the same school over a further 15-month period are reported. The biscuit was shown to be effective in improving the iron, iodine and vitamin A status of these 


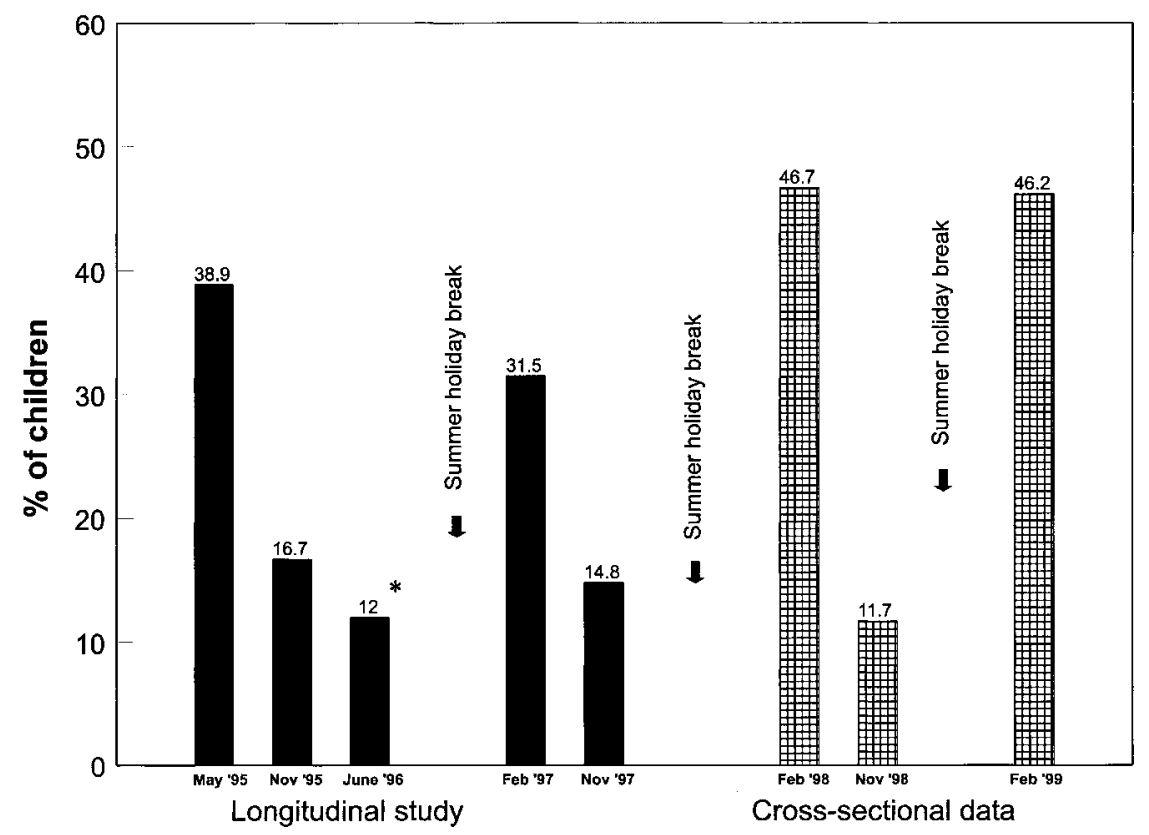

Fig. 1 The prevalence of low serum retinol levels $\left(<20 \mu \mathrm{g} \mathrm{dl}^{-1}\right)$ during the longitudinal study of 2.5 years, and at three subsequent crosssectional surveys conducted in the same school. ${ }^{*}$ Improvement at 12 months (June 1996) significant compared with a control group ${ }^{2}$

children during the first 12 months of intervention ${ }^{2}$; both vitamin $\mathrm{A}$ and iodine deficiencies improved from levels regarded as a severe public health problem $(>20 \%$ of a population with serum retinol $<20 \mu \mathrm{g} \mathrm{dl}{ }^{-1}$; median urinary iodine excretion $\left.<20 \mu \mathrm{g} \mathrm{l}^{-1}\right)^{7,8}$ to levels almost no longer regarded a problem. However, at the 21month assessment, which took place when the school reopened after the school holidays, a significant decline to pre-intervention status had occurred in serum retinol, serum ferritin, transferrin saturation and haemoglobin.

In South Africa, the academic school year usually lasts from late January to early December, followed by a long summer break of about 6-7 weeks. The biscuit programme was stopped in the middle of November 1996 (after the end-of-year school exams when there is usually a dramatic decline in school attendance in this community) and had

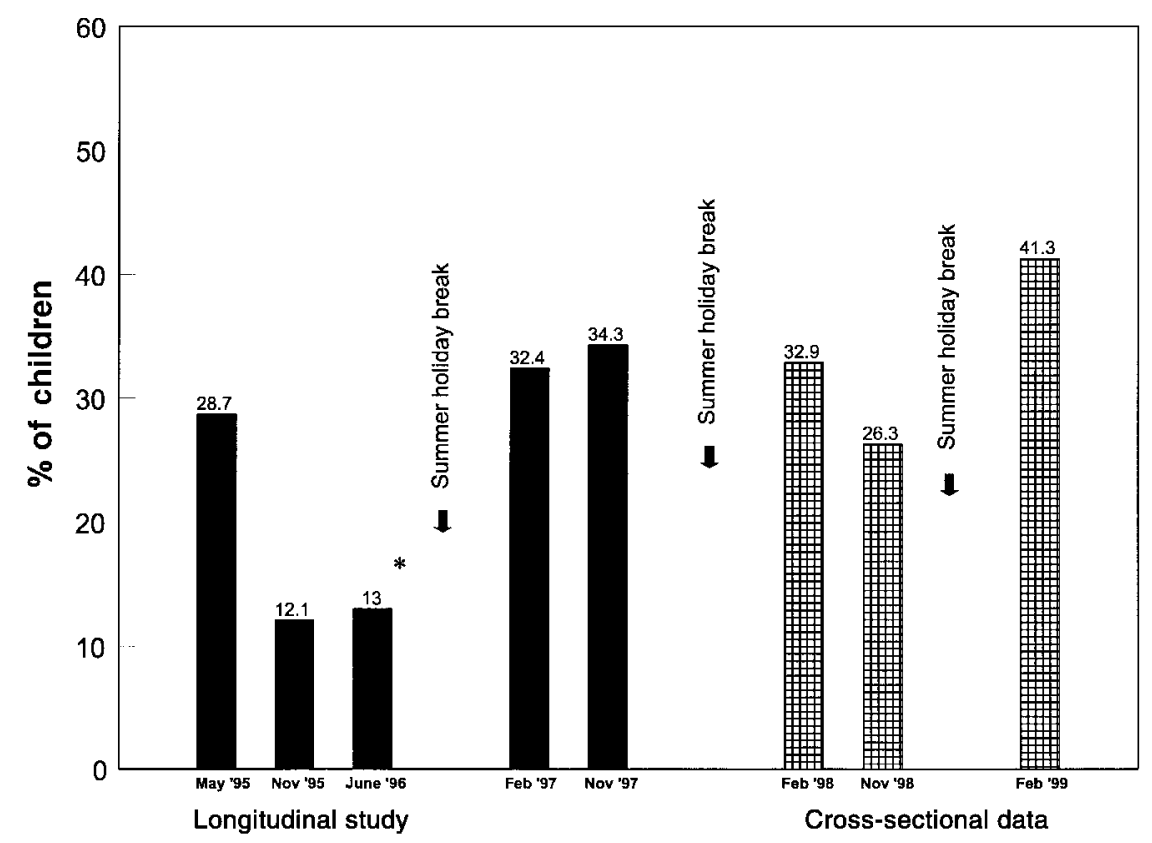

Fig. 2 The prevalence of low serum ferritin levels $\left(<20 \mu \mathrm{g} \mathrm{I}^{-1}\right)$ during the longitudinal study of 2.5 years, and at three subsequent crosssectional surveys conducted in the same school. ${ }^{*}$ Improvement at 12 months (June 1996) significant compared with a control group ${ }^{2}$ 
Table 2 The iron status of the children with baseline haemoglobin concentrations $<12 \mathrm{~g} \mathrm{dl}^{-1}$ during the 2.5 -year longitudinal study

\begin{tabular}{|c|c|c|c|c|c|}
\hline & $\begin{array}{c}\text { May } 1995 \\
0 \text { months } \\
(n=31)\end{array}$ & $\begin{array}{l}\text { Nov } 1995 \\
6 \text { months } \\
(n=31)\end{array}$ & $\begin{array}{c}\text { June } 1996 \\
12 \text { months } \\
(n=31)\end{array}$ & $\begin{array}{c}\text { Feb } 1997 \\
21 \text { months } \\
(n=31)\end{array}$ & $\begin{array}{c}\text { Nov } 1997 \\
30 \text { months } \\
(n=31)\end{array}$ \\
\hline Haemoglobin $\left(\mathrm{g} \mathrm{dl}^{-1}\right)$ & $11.63(0.36)$ & $11.76(0.60)^{\mathrm{NS}}$ & $12.28(0.66)^{\mathrm{a}}$ & $11.73(0.70)^{\mathrm{b}}$ & $11.60(0.59)^{\mathrm{NS}}$ \\
\hline Serum ferritin $\left(\mu \mathrm{g} \mathrm{I}^{-1}\right)$ & $32.0(9.9,52.6)$ & $30.3(15.3,59.7)^{\mathrm{NS}}$ & $38.5(17.8,50.3)^{N S}$ & $23.0(9.8,57.5)^{d}$ & $23.6(13.8,47.4)^{\mathrm{NS}}$ \\
\hline Serum iron $\left(\mu \mathrm{mol} \mathrm{I}{ }^{-1}\right)$ & $10.4(4.8)$ & $17.2(7.4)^{\mathrm{a}}$ & $16.6(6.3)^{\mathrm{a}}$ & $12.1(7.1)^{\mathrm{c}}$ & $14.7(5.8)^{\mathrm{d}}$ \\
\hline Transferrin saturation (\%) & $17.3(8.3)$ & $27.2(11.0)^{\mathrm{a}}$ & $26.3(11.2)^{a}$ & $18.2(8.4)^{c}$ & $23.3(10.6)^{d}$ \\
\hline
\end{tabular}

All values expressed as mean (SD), except for ferritin, which is expressed as median (10th, 90th percentile).

${ }^{\text {a }} P<0.0001$ compared with baseline; ${ }^{\mathrm{b}} P<0.0001,{ }^{\mathrm{c}} P<0.005,{ }^{\mathrm{d}} P<0.05$ compared with immediately preceding time point

$\mathrm{NS}=$ not significant compared with immediately preceding time point or with baseline for second and third surveys.

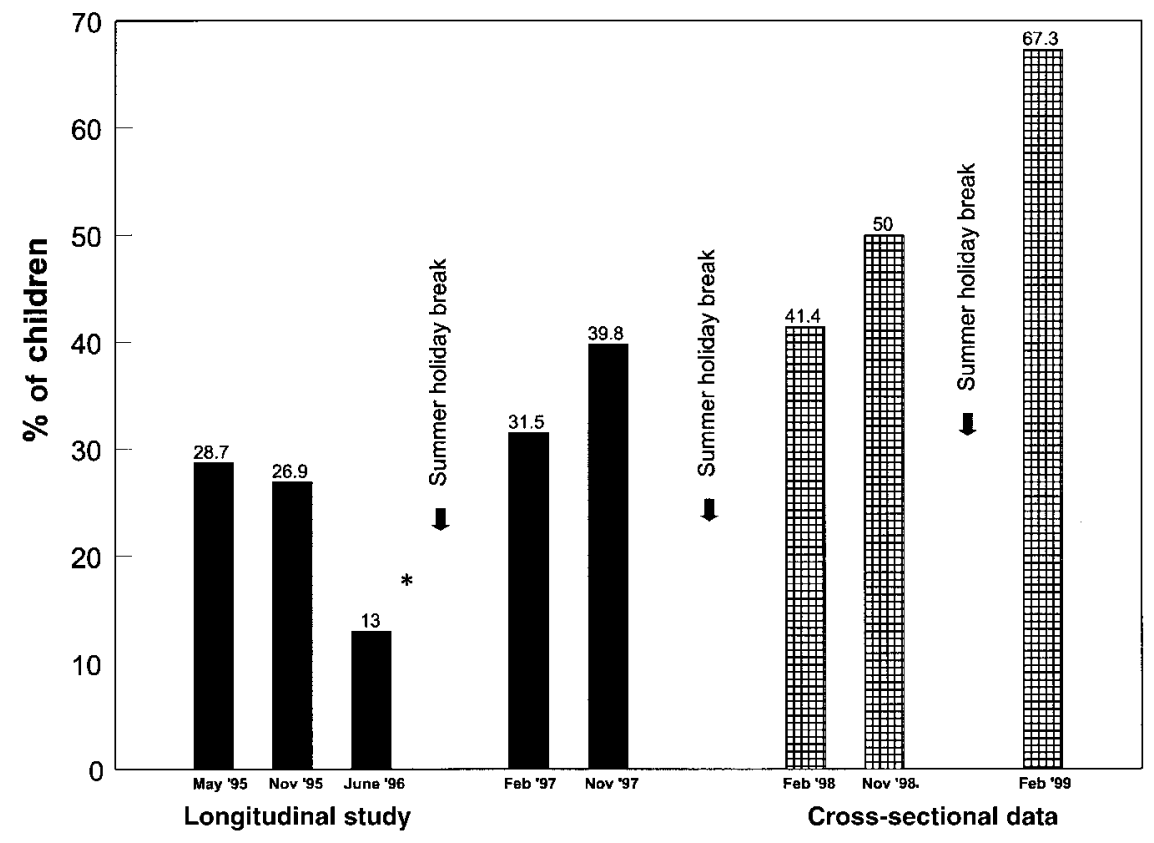

Fig. 3 The prevalence of low haemoglobin levels $\left(<12 \mathrm{~g} \mathrm{dl}^{-1}\right)$ during the longitudinal study of 2.5 years, and at three subsequent crosssectional surveys conducted in the same school. *Improvement at 12 months (June 1996) significant compared with a control group ${ }^{2}$

not been resumed at the time of the February 1997 survey. There was therefore a period of $\sim 10$ weeks during which the children were not exposed to the biscuit programme. The biscuits supplied 50\% of the daily RDA for vitamin $\mathrm{A}$ in the form of $\beta$-carotene. A recent survey ${ }^{9}$ of the dietary intake of the children in this school showed the median vitamin A intake to be $60 \%$ of the RDA; this included the $50 \%$ of the RDA that was supplied by the biscuit. Meals given to the child at home therefore contributed very little to the vitamin A intake of the child. It is therefore not surprising that serum retinol returned to pre-intervention levels during the time that the biscuit was not supplied. A similar drop in serum retinol was observed in the two subsequent cross-sectional surveys, which were also undertaken directly after the summer holidays for two consecutive years. The $\beta$-carotene

Table 3 Distribution of serum ferritin during the 2.5-year longitudinal study

\begin{tabular}{|c|c|c|c|c|c|}
\hline & \multicolumn{5}{|c|}{$\%$ of children } \\
\hline & $\begin{array}{l}\text { May } 1995 \\
0 \text { months } \\
(n=108)\end{array}$ & $\begin{array}{l}\text { Nov } 1995 \\
6 \text { months } \\
(n=108)\end{array}$ & $\begin{array}{l}\text { June } 1996 \\
12 \text { months } \\
(n=108)\end{array}$ & $\begin{array}{c}\text { Feb } 1997 \\
21 \text { months } \\
(n=108)\end{array}$ & $\begin{array}{c}\text { Nov } 1997 \\
30 \text { months } \\
(n=108)\end{array}$ \\
\hline \multicolumn{6}{|l|}{ Serum ferritin } \\
\hline$<10 \mu \mathrm{g} \mathrm{I}^{-1}$ & 5.6 & 0.9 & 0.9 & 5.6 & 4.6 \\
\hline $10-19.9 \mu \mathrm{gl}^{-1}$ & 23.1 & 11.2 & 12.0 & 26.9 & 29.6 \\
\hline $20-59.9 \mu \mathrm{g} \mathrm{I}^{-1}$ & 62.0 & 75.7 & 78.7 & 60.2 & 61.1 \\
\hline $60-99.9 \mu \mathrm{g} \mathrm{I}^{-1}$ & 7.4 & 10.3 & 6.5 & 6.5 & 3.7 \\
\hline$>100 \mu \mathrm{g} \mathrm{I}^{-1}$ & 1.9 & 1.9 & 1.9 & 0.9 & 0.9 \\
\hline
\end{tabular}




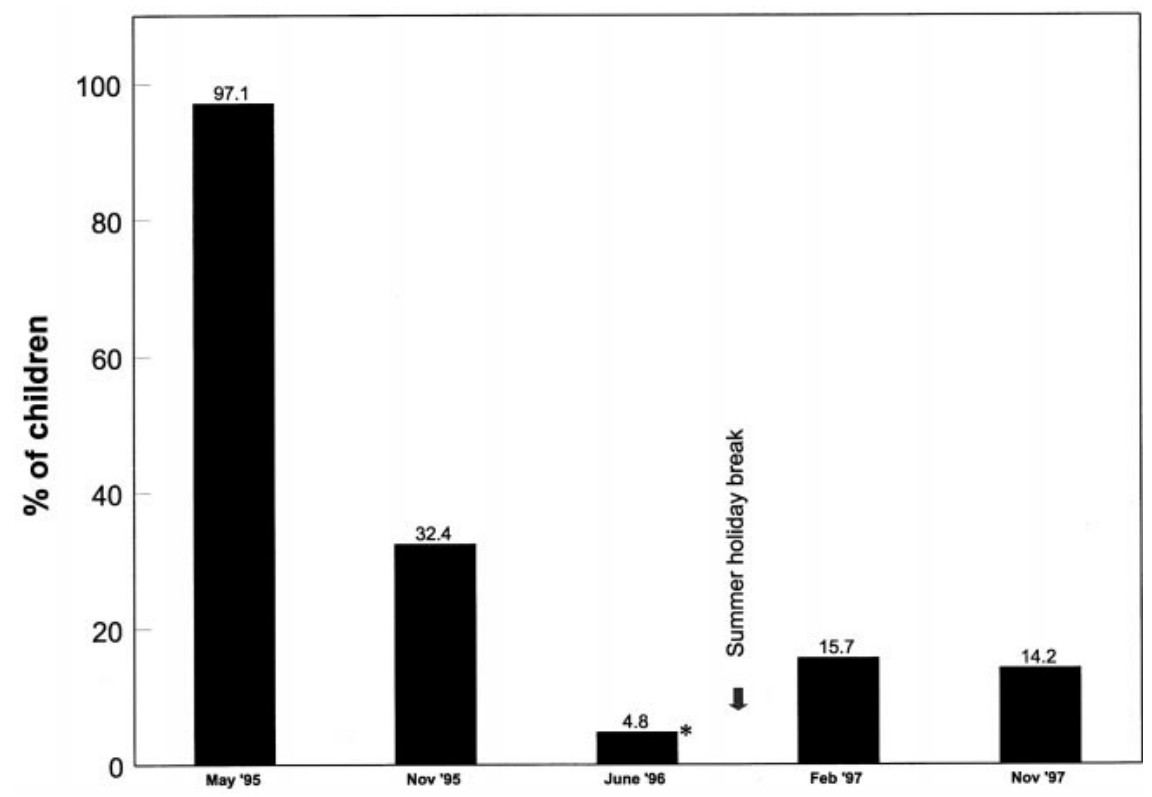

Fig. 4 The prevalence of low urinary iodine levels $\left(<100 \mu \mathrm{g} \mathrm{I}^{-1}\right)$ during the longitudinal study of 2.5 years. ${ }^{*}$ Improvement at 12 months (June 1996) significant compared with a control group ${ }^{2}$

supplied by the biscuit was probably just enough to maintain serum retinol levels from day to day, but not sufficient to replenish stores or to maintain existing stores during periods when the biscuit was not consumed. There are indications from studies in rodents ${ }^{10}$ that previously fed $\beta$-carotene present in the tissues is lost rapidly and not conserved for later use as a source of vitamin A, not even during periods of compromised vitamin A status; whether these results are applicable to humans, however, is not known.

Several options are available to overcome the problem of serum retinol levels that are not maintained during the long school holiday breaks. Increasing the amount of $\beta$ carotene added to the biscuits is one solution. However, if $\beta$-carotene cannot be stored for later use as a source of vitamin $\mathrm{A}^{10}$ this exercise would be futile, and the use of vitamin $\mathrm{A}$ as fortificant, rather than $\beta$-carotene, would be a better option. Excessive intake of vitamin A in this case would be unlikely, because the number of biscuits given to the children in a school setting is regulated. However, the best long-term solution in a community such as this would be to supplement the biscuit programme with nutrition education, as well as with a local home gardening programme that encourages the production and consumption of foods rich in $\beta$-carotene.

All the indicators of iron status declined to preintervention levels after the holiday break at 21 months, in both the group as a whole and in those who were anaemic at the start of the study. The dietary survey? undertaken in this community showed that the median intake of iron (which included the $5 \mathrm{mg}$ supplied by the three biscuits) was 109\% of the RDA; the diet at home thus supplied $60 \%$ of the RDA. However, because of low bioavailability of the iron (mostly of plant origin and with low vitamin $\mathrm{C}$ intake), this amount may not have been enough to sustain blood levels during the holiday period. Only serum iron and transferrin saturation improved during the following 9 months, but not by the earlier magnitude; there was no response in haemoglobin or serum ferritin, not even in those who were anaemic. A vitamin-C-fortified cold drink to enhance the absorption of iron was provided together with the biscuit. This practice was meticulously adhered to during the first 18 months of the study. However, due to logistical problems with regard to the manufacture and supply of the vitaminC-fortified cold drink, it was provided on a less frequent basis during the last 9 months. This may have resulted in poorer absorption of iron from the biscuit. It has been demonstrated that ascorbic acid, given in the same meal, can increase iron absorption several fold ${ }^{11,12}$.

A more bioavailable form of iron, i.e. an iron amino acid chelate (ferrous bisglycinate), was used as fortificant during the cross-sectional phase of the study, and the cold drink was no longer supplied. Although there was some improvement in serum ferritin at 42 months, haemoglobin deteriorated further. Because all of the children received the micronutrient-fortified biscuit, there was no control group and no conclusions with regard to the efficacy of the iron amino acid chelate used as fortificant in the biscuit can be made. In other studies that showed ferrous bisglycinate to be effective in the treatment of anaemia, the chelated iron was either given in the form of tablets ${ }^{13}$ or was used as fortificant in products that were not baked for long periods ${ }^{14}$ or not baked at all ${ }^{15}$. Our fortified biscuit was baked at a temperature of $210^{\circ} \mathrm{C}$ for $\sim 20$ minutes and it is possible that degradation of the chelate 
might have taken place at this temperature. According to Albion Laboratories, Inc. ${ }^{16}$ it is not recommended that ferrous bisglycinate is heated by itself above $153^{\circ} \mathrm{C}$, because decomposition of the amino acids and subsequent oxidation of the iron can take place. When added to products that are subsequently cooked, higher ambient temperatures may be used, because the degree of destruction will depend on the internal temperature of the food being cooked. An ambient temperature above $200^{\circ} \mathrm{C}$ may, however, have been too high for the ferrous bisglycinate to survive in the biscuits. This needs further investigation.

With any iron intervention the risk of iron overload should be considered. In Africa, iron overload may be caused by excessive intake of iron resulting from brewing beer in iron pots, as well as a genetic predisposition which is unrelated to HLA-linked haemochromatosis ${ }^{17}$. For this intervention, however, the risk of iron overload is unlikely. The fortified biscuit intervention is targeted at primary school children only and the amount of iron contributed by the biscuits is only $5 \mathrm{mg}$ per day (supplied for $\sim 50 \%$ of the year only), which is negligible compared with intakes that may result from consumption of traditional beers. Furthermore, the results of our study show a general deterioration in iron status over time, with very few children having serum ferritin levels in excess of $100 \mu \mathrm{g} \mathrm{l}^{-1}$. The latter were more likely to be the result of infection $^{18}$, as not a single child had consistently high levels of serum ferritin throughout the study and in all cases ferritin levels above $100 \mu \mathrm{g} \mathrm{l}^{-1}$ were associated with either elevated C-reactive protein or elevated white blood cell concentrations.

The general deterioration in serum ferritin over time is difficult to explain. It is possible that that the iron deficiency that may have been prevalent at baseline was masked by a higher infection rate at that time, which declined as a result of the intervention, simultaneously resulting in a normalisation of the serum ferritin levels. Hulthén et $a l .{ }^{19}$ reported a marked shift in serum ferritin towards higher values in adolescents with upper respiratory infections during the month preceding their survey. We unfortunately do not have data on C-reactive protein available for all of our eight surveys. However, mean white blood cell counts do show a gradual deterioration over time, with counts from the fourth survey onwards being significantly lower than the count at baseline. A decline in infection rate therefore may have contributed to the decrease in ferritin levels. The gradual decline observed for haemoglobin also, however, suggests that the decline in infection rate was not the only explanation for the decrease in ferritin levels and that some deterioration in iron status did indeed take place.

In cohort studies involving growing children the potential confounding effect of age on nutritional variables should be borne in mind. It is, however, unlikely that age had an effect on the results of our study. We analysed a subgroup of children (including only children aged 8-11 years for each of the eight surveys) and found the pattern to be identical to that reported for the whole group (data not shown). This excludes the possibility that age played a confounding role in the fluctuations in micronutrient status observed in our study.

Only iodine status did not return to pre-intervention levels after the school holiday break; median urinary iodine excretion was maintained well above the acceptable level of $100 \mu \mathrm{g}^{-1}$ throughout the study. This was probably because of the iodisation of salt, which became compulsory in South Africa in December 1995, six months after the start of our intervention. Iodised salt was available in all of the local shops in the area and the salt was used by all households in the preparation of food. There is therefore no further need to add iodine to a fortified biscuit distributed in South African schools. The effectiveness of the mandatory salt iodisation programme in South Africa was evaluated by Jooste et al. ${ }^{20}$ and shown to be effective in virtually eradicating iodine deficiency, as measured by urinary iodine excretion, in a group of school children within one year.

Distributing the biscuits at school appeared not to have had an effect on breakfast consumption. The percentage of children who reported eating breakfast before the start of the biscuit intervention was around 90\%; this figure remained so throughout the study. None of the children gave the biscuit given at school as a reason for not eating breakfast. This confirms the notion that the biscuit is perceived as a snack and not as a meal, and that it is unlikely to replace meals given to the child at home. After 2.5 years on the biscuit programme the biscuit was still well liked by all of the children and $78.5 \%$ indicated that they would prefer more than the three biscuits they were receiving.

In conclusion, this study has shown that fortification of a biscuit with $\beta$-carotene at a level of $50 \%$ of the RDA was enough to maintain serum retinol concentrations at acceptable levels from day to day, but not enough to sustain levels during a break of 10 weeks, especially if intake from other sources is insufficient. Long-term solutions such as local food production programmes combined with nutrition education should also be sought. It would also appear that the bioavailability of ferrous fumarate in the biscuit without the vitamin-C-fortified drink is inadequate. The effectiveness of using a chelated form of iron as fortificant in the biscuit needs further investigation.

\section{Acknowledgements}

We thank Eldrich Harmse, Martelle Marais and De Wet Marais for their excellent technical support; the headmaster, staff and pupils of the Ndunakazi Primary School for their friendly co-operation; the team of nutrition monitors for their invaluable support and dedication to 
the study; SASKO Pty, Ltd for financial support and for supplying the fortified biscuits; and SmithKline Beecham Pharmaceuticals Pty, Ltd for donating the anthelmintic tablets.

\section{References}

1 Ramalingaswami V. Challenges and opportunities - one vitamin, two minerals. World Health Forum 1992; 13: 222 31.

2 Van Stuijvenberg ME, Kvalsvig JD, Faber M, Kruger M, Kenoyer DG, Benadé AJS. Effect of iron-, iodine-, and $\beta$ carotene-fortified biscuits on the micronutrient status of primary school children: a randomized controlled trial. $A m$. J. Clin. Nutr. 1999; 69: 497-503 [erratum in Am. J. Clin. Nutr. 1999; 69: 1294].

3 National Research Council. Recommended Dietary Allowances, 10th ed. Washington, DC: National Academy Press, 1989.

4 Catignani GL, Bieri JG. Simultaneous determination of retinol and $\alpha$-tocopherol in serum or plasma by liquid chromatography. Clin. Chem. 1983; 29: 708-12.

5 Dunn JT, Crutchfield HE, Gutekunst R, Dunn AD. Methods for Measuring Iodine in Urine. The Hague: International Council for Control of Iodine Deficiency Disorders, 1993; $1-60$.

6 Tichelaar HY, Smuts CM, Kvalsvig JD, Van Stuijvenberg ME, Laubscher R, Faber M, Benadé AJS. Randomised study of cognitive effects of $\omega 3$ fatty acid supplementation in undernourished rural school children. S. Afr. J. Clin. Nutr. 2000; 13: 100 [abstract].

7 World Health Organization (WHO). Indicators for Assessing Vitamin A Deficiency and Their Application in Monitoring and Evaluating Intervention Programmes. Geneva: World Health Organization, 1996.

8 WHO/UNICEF/ICCIDD. Indicators for Assessing Iodine Deficiency Disorders and Their Control Through Salt Iodization. Geneva: World Health Organization, 1994.

9 Faber M, Smuts CM, Benadé AJS. Dietary intake of primary school children in relation to food production in a rural area in KwaZulu-Natal, South Africa. Int. J. Food Sci. Nutr. 1999; 50: $57-64$.

10 Thatcher AJ, Lee CM, Erdman JW. Tissue stores of $\beta$ carotene are not conserved for later use as a source of vitamin A during compromised vitamin A status in Mongolian gerbils. J. Nutr. 1998; 128: 1179-85.

11 Siegenberg D, Baynes RD, Bothwell TH, Macfarlane BJ, Lamparelli RD, Car NG, MacPhail P, Schmidt U, Tal A, Mayat F. Ascorbic acid prevents the dose-dependent inhibitory effects of polyphenols and phytates on nonheme-iron absorption. Am. J. Clin. Nutr. 1991; 53: 537-41.

12 Derman D, Sayer M, Lynch SR, Charlton RW, Bothwell TH. Iron absorption from a cereal-based meal containing cane sugar fortified with ascorbic acid. Br. J. Nutr. 1977; 38: 261-9.

13 Pineda O, Ashmead HD, Perez JM, Lemus CP. Effectiveness of iron amino acid chelate on the treatment of iron deficiency anemia in adolescents. J. Appl. Nutr. 1994; 46: $2-13$.

14 Name JJ. Food fortification with amino acid chelated minerals. Seminar on Food Fortification for Better Living, Cairo, Egypt, 16 September 1995.

15 Iost C, Name JJ, Jeppsen RB, Ashmead HD. Repleting hemoglobin in iron deficiency anemia in young children through liquid milk fortification with bioavailable iron amino acid chelate. J. Am. Coll. Nutr. 1998; 17: 187-94.

16 Albion Laboratories, Inc. Ferrochel Technical Monograph. UT, USA: Albion Laboratories, Inc., 1995; 16.

17 Gordeuk V, Mukiibi J, Hasstedt SJ, et al. Iron overload in Africa. Interaction between a gene and dietary iron content. N. Engl. J. Med. 1992; 326: 95-100.

18 Witte DL. Can serum ferritin be effectively interpreted in the presence of the acute-phase response? Clin. Chem. 1991; 37: 484-5.

19 Hulthén L, Lindstedt G, Lundberg P-A, Hallberg L. Effect of a mild infection on serum ferritin concentration - clinical and epidemiological implications. Eur. J. Clin. Nutr. 1998; 52: $376-9$.

20 Jooste PL, Weight MJ, Lombard CJ. Short-term effectiveness of mandatory iodization of table salt, at an elevated iodine concentration, on the iodine and goiter status of schoolchildren with endemic goiter. Am. J. Clin. Nutr. 2000; 71: $75-80$. 